\title{
Artist's book Poor Fish Memories in digital version
}

\author{
Irene de Mendonça Peixoto \\ Escola de Belas Artes-UFRJ| Brazil | peixotoirene@gmail.com \\ Felipe de Souza \\ Aspecto Design de Soluções | Brazil | felipe@aspectos.com.br \\ José Carlos de Pontes \\ Multi Arte Brasil | Brazil | zeca@multiartebrasil.com.br
}

\begin{abstract}
The passages and combinations between analog and digital languages point to issues that have persisted for decades and which continue to foster contemporary, ethical and aesthetic debates about experience and temporality. Problematizing these questions, we extend the discussion to the importance of contemporary design to adopt creative strategies that articulate thoughts from other areas of knowledge, such as philosophy and art, from the perspective of multiplicity of mediums. The intention is to oxygenate classic design issues, such as conception, form creation, and user interaction, through the provocative sensory and temporal displacements that artistic creation promotes.
\end{abstract}

Keywords: Art; Design; Aesthetic experience; Temporality.

\section{INTRODUÇÃO}

O presente trabalho problematiza as questões conceituais incursas nas etapas de transposição de um trabalho de arte gráfica impressa para uma plataforma digital. Sob o ponto de vista técnico, a obra gráfica inicialmente concebida é uma ambientação que propõe a leitura de um livro que condensa em sua composição vários suportes: vídeo projetado sobre suas páginas, desenhos aquarelados e a impressão digital que concretiza o corpo físico do livro-objeto.

A realização do mesmo trabalho em versão digital on-line teve como principal desafio não perder a sintonia com o princípio que norteia a construção poética do livro físico. Nomeado Poor Fish Memories, esse projeto atua nos campos ampliados do design e da arte e foi criado dentro de uma proposta ética e estética que se alinha às críticas do pensamento contemporâneo, ao modo como a modernidade compreendeu as relações entre passado, presente e futuro.

A metodologia aplicada às demandas técnicas do projeto foi considerada a partir das questões conceituais implicadas no trabalho. Questões essas que tratam do fim das utopias modernas que priorizavam o futuro em detrimento do presente e de seus desdobramentos rumo a uma sociedade contemporânea orientada para soluções fáceis e de pronto uso. Não é fortuito que os criadores de nosso tempo se voltem para uma temporalidade mais lenta, para um indefinido tempo presente no qual os processos ganham relevância sobre os resultados. O livro Poor Fish Memories além de ser um projeto de design gráfico, é um gesto poético ofertado ao mundo. Por isso, o que precisou ser preservado na passagem para a versão on-line foi justamente essa possibilidade de leitura onírica permeada por um olhar descompromissado.

\section{EIXOS CONCEITUAIS}

Para um melhor entendimento das intenções conceituais que nortearam o projeto, fazendo com que a sua forma nascesse em franca colaboração com essas intenções, cabe trazer aqui algumas considerações de Boris Groys (2009) sobre as questões abordadas. O autor afirma que a modernidade considerou o presente um entrave para a chegada do futuro, um embaraço retardando a chegada gloriosa desse tempo no qual todas as utopias poderiam se realizar. Sobre o passado, podemos emitir nossas certezas, confirmar nossas conclusões, mas o presente nos faz titubear. O presente é um tempo de hesitação, dúvidas, perplexidade. É quando os acontecimentos nos escapam, o que imaginávamos não se realiza, somos surpreendidos. Precisamos adiar nossas decisões e ações a fim de ter mais tempo para pensar, refazer, duvidar. Para Groys, o presente contemporâneo se caracteriza precisamente por essas incessantes reavaliações, não só de nosso fazer cotidiano mas também de todas as nossas heranças modernas. Por isso torna-se preciso provocar deslocamentos sensoriais, intensificar nosso tempo presente para aprendermos a habitá-lo como se fosse um tempo desconhecido.

A modernidade enalteceu o futuro, estabeleceu suas razões sobre a capacidade dos tempos vindouros de realizar os anseios do passado e do presente. Hoje, essa quimera de um futuro infinito assegurando as ilações de nossa atividade presente perdeu sua plausibilidade. Nossos horizontes se tornaram infinitamente complexos e instáveis. Talvez seja por isso que na arte contemporânea os processos ganharam relevância sobre 
os resultados. A arte deixa de estar no presente, entendido apenas como a instantaneidade do aqui-eagora, para evidenciar um repetitivo e, talvez infinito
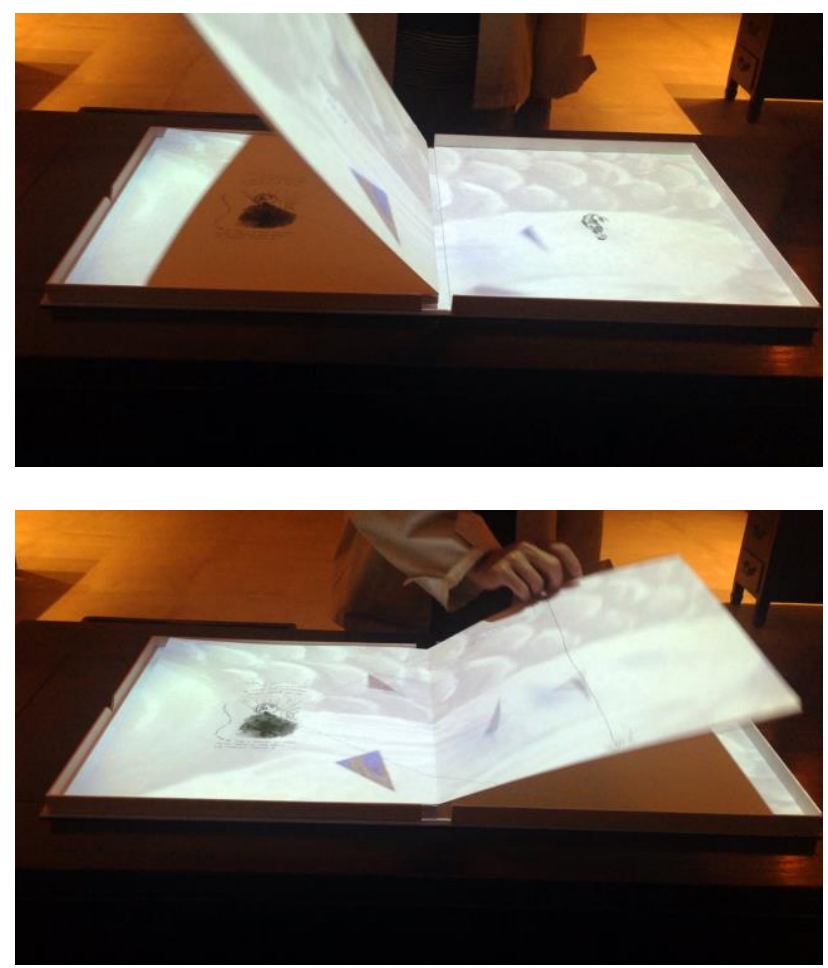

Figuras 1 e 2: Livro-objeto Poor Fish Memories com o vídeo projetado em suas páginas durante o manuseio. Fonte: Autores.

presente - "um presente que já estava lá desde sempre, e que pode se prolongar indefinidamente" (Groys, 2009, p. 7).

Os artistas contemporâneos nos apresentam trabalhos que ocorrem no tempo, mas não levam à criação de qualquer produto em definitivo. São trabalhos que tematizam ações ausentes, sem sentido ou finalidade explícita. Assim, as poéticas contemporâneas nos libertam desse incomensurável presente, que se tornou um lugar óbvio de ressignificação permanente do passado e do futuro, das incontáveis narrativas históricas que proliferam indefinidamente, desqualificando nossos atos e pensamentos, gerando o temor da improdutividade, do tempo perdido de forma que os tempos improdutivos são frequentemente excluídos, temidos e condenados nas narrativas históricas de nossa atual civilização, orientada para resultados de pronto uso.

A arte, e também o design, podem nos ensinar a acolher esse tempo de desperdício sob outro ponto de vista ao evidenciar a nossa impossibilidade para dar conta dos acontecimentos, de todos os estímulos ao qual estamos expostos. Em face à essa complexidade, as poéticas contemporâneas sentem a necessidade de utilizar diversas mídias. $\mathrm{O}$ pensamento sobre um único projeto pode se desmembrar em uma enorme variedade de suportes. Frente a tantas presentificações, é quase impossível acompanhar todos os vetores poéticos que irradiam do conjunto, nossos julgamentos se estilhaçam. A escassez de tempo se torna tão evidente que desistimos de recorrer ao entendimento e nos deixamos levar pela correnteza das sensações. $\bigcirc$ aflitivo desconforto provocado pela incapacidade de ferirmos o ponto da obra, de fechar conclusões sem perda de tempo, é aplacado pela irresistível tentação e deleite em aprofundar a nossa fruição nessa região indomável e livre, mas também detentora de inexplicável rigor.

Os criadores contemporâneos confrontam esse terror ao improdutivo, ao desperdício, através de um tempo que não se deixa otimizar pelo espectador. As trocas íntimas, as incertezas dos artistas enunciadas em suas obras, a sua complexidade, tornariam vão qualquer investimento de tempo que pretenda reduzir a atividade artística a um pensamento simples e abstrato. "Resumir uma tese é reter-Ihe o essencial, resumir uma obra de arte é perderIhe o essencial" (Valery, 2006, p. 203). Por isso, quando percebemos a impossibilidade da tarefa e, mais ainda, quando aceitamos como benéfica a sua inutilidade, nos libertamos do fardo imperativo de tudo querer compreender para adentramos em um tempo suspenso no qual essa inexplicável improdutividade pode ser bem acolhida, o arbitrário e o necessário se conjugam.

Groys (2009) conota um significado diferente à palavra contemporâneo. Para ele, ser contemporâneo não significa necessariamente estar presente, estar aqui-eagora, "significa estar junto com o tempo em vez de estar no tempo, o que em alemão é zeitgenössisch. Como genosse significa ser camarada, colaborador, ser contemporâneo (zeitgenössisch) pode, portanto, ser entendido como ser um companheiro de tempo" (p. 6). Assim, a criação contemporânea, ao transformar a escassez de tempo em excesso, colabora com o tempo, invertendo a noção negativa de tempo perdido e improdutivo, afirmando e conferindo para essa "improdutividade" a soberania e a liberdade do tempo poético. Segundo Groys, esse é o ponto preciso, em que a arte pode verdadeiramente ser uma companheira do tempo, ou melhor dizendo, ser arte contemporânea.

É próprio do pensamento criador estabelecer uma relação incomum com o tempo, como uma ruptura na continuidade da vida, um excesso de tempo fora da história. Uma vez ativados os valores de suspensão, o objeto poético compartilha conosco a sua temporalidade encantada, onde o tempo sem medida se torna, por isso mesmo, em tempo imensurável - a escassez se converte em excesso. Esse tempo "de sobra" ignora as linhas que o amarram do passado ao futuro, se verticaliza na convergência dos contrários revelando as dimensões secretas por onde as relações entre matéria e espírito se alteram, um se tornando outro continuamente.

Esse "tempo improdutivo" se aplica ao projeto Poor Fish Memories. Foi através da subversão da noção negativa do tempo perdido que o folhear distraído, proposto no trabalho, sem intenção de leitura linear, nem a compreensão de um todo, pôde positivar o tempo dessa leitura excessiva, desperdiçada tornando-a uma leitura poética. Essas foram as questões que permearam o realizar do trabalho na sua dimensão física.

Nas suas páginas, a matéria do papel deixa de ser apenas suporte para se tornar elemento participativo do trabalho. A aparência silenciosa da folha em branco amplia a importância do vazio na composição dos desenhos pequenos e concentrados em áreas 
desordenadas da página. A brancura se estende, se torna uma tela para receber a projeção do vídeo. O contexto fabular do livro é intencionalmente intricado e sinuoso. As histórias inventadas participam de outras que fantasiam realidades incertas. Os indícios, os rastros de existência só importam quando acolhidos pela ficção.

\section{METODOLOGIA}

Do ponto de vista técnico, a versão digital foi desenvolvida na plataforma de CMS Wordpress (https://codex.wordpress.org/pt-br:WordPress) com apoio do complemento plugin LayerSlider 6, conjunto de ferramentas utilizado na realização do projeto. $\mathrm{Na}$ primeira etapa definiu-se o fluxo dos movimentos animados, o roteiro de paginações e a hierarquia de entrada e saída dos elementos e demais questões técnicas, como proporção e formato responsivo para exibição em diferentes plataformas.

Para a transposição da narrativa do material físico para o material digital, foram elaborados storyboards com a sequência de quadros e previsão de elementos e movimentos em cada um. A intenção foi de preservar ao máximo a fidelidade do material original. Para isso foram previstas, nas telas da animação, haver mais de um momento de leitura e exibição dos elementos, visando sempre respeitar as folhas e páginas do original, assim como os elementos que estavam dispostos e ligados, às vezes por linhas do próprio desenho ou apenas por movimento visual.

Para a navegação, foram estabelecidas setas ao término de cada tela, que correspondiam a duas páginas abertas, para "passar" ou "recuar" entre a sequência de telas. As imagens e textos originais foram manipulados e tratados para se chegar nas devidas proporções e resoluções adequadas em programas de edição de imagem como Photoshop, separando os elementos conforme definidos antes.

O vídeo da animação do "ballet dos papéis", tema e inspiração para o trabalho, foi usado como background, com reprodução em looping constante durante todo 0 tempo em que as animações estivessem disponíveis. Foi uma parte grande do desafio configurar esse material para uma boa exibição em determinados tipos de visualizadores, principalmente os celulares da Apple IOS onde uma série de restrições do navegador nativo do sistema, o Safari, dificultavam uma correta exibição com o arquivo do filme em formato MP4. Por isso, extensões foram adicionadas para que cada navegador "escolhesse" dentro de suas configurações qual era a melhor para a correta exibição. As extensões citadas foram animação em GIF e vídeo WEBM.

Mas como transpor o "folhear distraído" do livro físico para o ambiente eletrônico das telas de computador?

O projeto inicial de Poor Fish Memories propõe um livro de porte grande para ser lido em pé sobre uma mesa, por isso o ato de folhear, assim como a atenção do olhar, implica na articulação de vários músculos do corpo. Os diferentes suportes técnicos, o vídeo projetado sobre as páginas, os desenhos e a própria superfície do papel impresso ajudam a criar o ambiente imersivo/dispersivo fundamental para que a vagueação poética aconteça. No livro físico, figura (desenhos) e fundo (vídeo) se misturam, mas também se diferenciam pelas superfícies do que é projeção e impresso. O mover das páginas acontece em paralelo, mas de forma independente à movimentação do vídeo.

Já no ambiente digital tudo é luz, figura e fundo não se misturam nem se diferenciam da mesma forma, e o folhear de páginas se dá com um discreto toque dos dedos na tela ou no clique do mouse. Para criar a imersão/dispersão desejada para a fruição poética foi preciso recorrer a outros artifícios. O movimento corporal do ato de folhear foi deslocado para o olhar que passa a acompanhar a animação dos desenhos que antes eram estáticos. A simultaneidade das duas animações, do vídeo e dos desenhos, exige mais atenção e agilidade do olhar na alternância de foco entre figura e fundo, ambas, agora, luz em movimento. A autonomia de ir e vir no livro físico pelo folhear das páginas foi em parte respeitada pelos recursos de navegação, mas a animação dos desenhos impõe o seu ritmo ao leitor, fazendo que ele seja obrigado a uma espera que é também um convite a demorar/vaguear o seu olhar para outros detalhes dentro daquela cena visual. Tal como no livro físico, o leitor será impelido a navegar pela versão on-line em franca deambulação, abandonando a leitura linear e compreendendo o trabalho por suas partes fragmentadas.
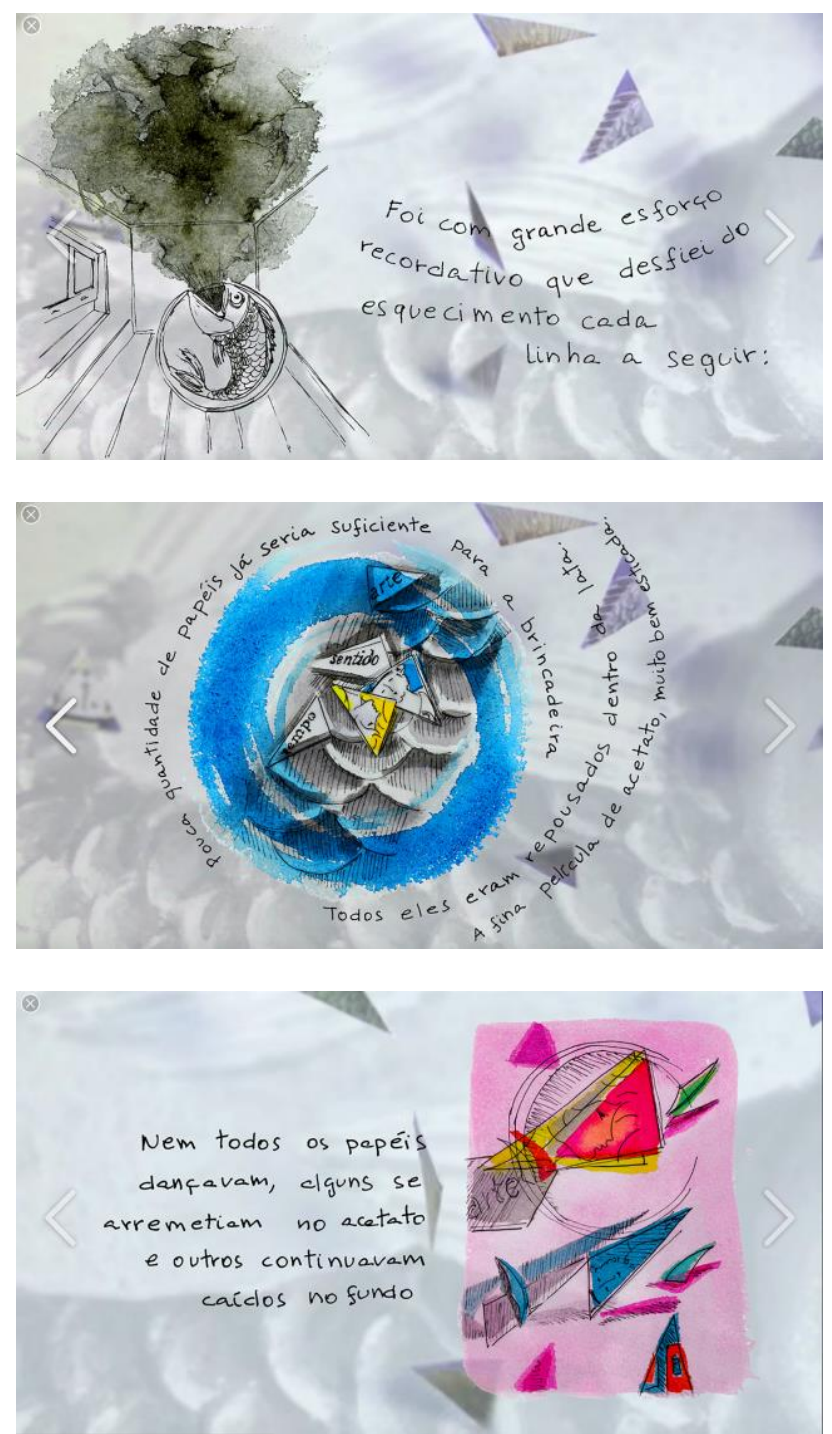

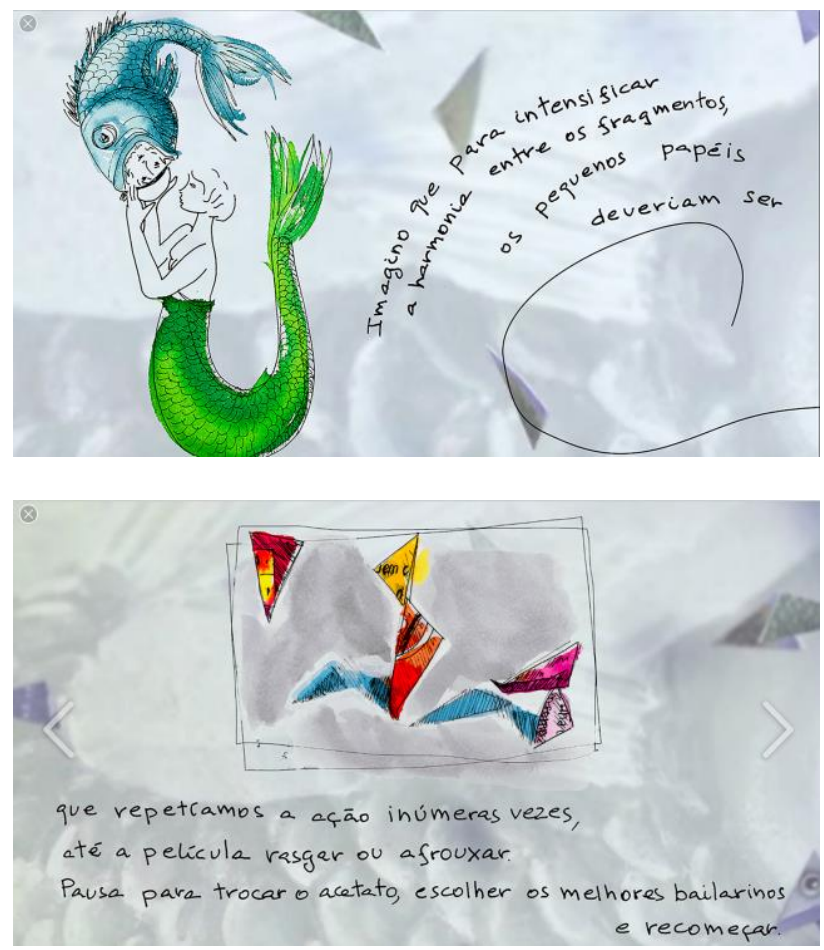

Figuras 3, 4, 5, 6 e 7: frames da versão do livro on-line. Fonte: Autores.

O importante nas duas versões é desafiar o leitor/usuário a habitar uma complexidade, o que implica a evidência que uma compreensão imediata do todo da obra não é só impossível, mas indesejável. Ao contrário da objetividade da leitura linear, o que se aspira é através dos campos ampliados entre arte e design apreender, como diria o artista Tunga (2017), "a lógica do brincar e o rigor da distração" (p.82).

\section{RESULTADOS}

E qual a contribuição de todo esse processo para o design? O designer/filósofo Henrique Antoun (1990) nos oferece uma resposta ao discorrer sobre as sensações que um projeto de design gráfico pode despertar: "uma textura que granula uma tinta, uma opacidade que recobre uma transparência, um deslocamento que convida ao encaixe e temos um objeto pronto para sua encenação visual. Objeto que descrito não nos dá uma imagem. Objeto que lembrado exige ser visto" (p.2).

Que objeto é esse que nos convida ao infinito? Será mesmo um objeto? Que encenação visual é essa? Será mesmo uma visualidade? Não se trata apenas de ver, mas de modos de ver, modos de sentir, modos de estar no mundo.

Ver além do finito que nos rodeia implica em ir além de nossa própria finitude. É expandir o que vemos, provocando o uso transcendente da visão. É perceber o "extra" que transborda do ordinário das coisas. É compreender que a potência dos acontecimentos está nesses transbordamentos, nas relações que estabelecemos com o mundo à nossa volta.

Um olhar que pensa, que relaciona, se descola do finito do visto (das coisas, dos objetos acabados) e se lança ao infinito do olhar (das relações, sempre mutantes, entre as coisas). Esse olhar transcendente nos convida a ultrapassar as fronteiras de nossa experiência ordinária do mundo (sucessiva e linear) para liberar o fluxo intenso da vida que nos potencializa, nos faz pensar 0 impensável, e imaginar o inimaginável, que nos ensina a habitar o tempo das intensidades (Deleuze,1992).

A intensidade é o movimento do imóvel. Esse movimento do intenso não se efetua nos corpos, mas se expressa, por isso prescinde da movimentação dos mesmos. O que podemos entender por expressão? A expressão é uma existência velada desses movimentos intensos que, por algum uso transcendente de nossas faculdades, torna-se visível. Expressão é o que disseram Paul Klee e Cézanne de suas próprias poéticas. Ambos queriam "tornar visível o invisível" (Klee, 2007, p. 35).

Fazer visível, pensar visível. Compreender o que vemos como potência de atualização, dando exposição a processos criadores que formam, deformam e transformam. Compreender o visível na sua capacidade de expressar valores, conceitos, significados que extrapolam a própria visibilidade é uma questão da arte e também do design. Entender os processos criativos como expressão de afetos - incorporais que transbordam dos corpos - é buscar nas obras as potências que as atravessam. As inquietações que movem os criadores só podem ser expressas no exercício de uma poética.

O que é, no contexto de minhas pesquisas, uma poética? As palavras de origem grega poiétiké e poiésis se formam diretamente sobre poiein que significa fazer ou fabricar. A noção clássica da palavra pode ser compreendida como o estudo de uma obra a ser feita. Para Umberto Eco (1991), ela emana do discurso criador, de como o artista compreende o fazer de sua própria obra de um modo tal que o objeto artístico contenha os indícios de sua intenção. Assim, uma constituição poética é uma chamada livre para adentrarmos em um universo desconhecido, mas que de uma forma ou de outra pertence ao artista que o criou.

A palavra design é uma expressão inglesa, vinda do latim designiu que significa plano, propósito, projeto. Um projeto de design se caracteriza justamente por um pensar/fazer que compreende imaginação, conceito e projeto. Não podemos criar sem ao mesmo tempo pensar como o projeto será realizado, principalmente porque projetamos, a princípio, para uma fabricação industrial.

Retomando a noção clássica de poética que é o estudo para uma obra ser feita, podemos encontrar afinidades entre as definições de poética e design. Porém, uma poética comporta bem mais do que pensar-como-fazerum-projeto, ela supõe uma intencionalidade de outra ordem. A importância dada aos métodos, aos procedimentos, são frutos de um pensamento que problematiza o mundo.

E o problema, vai nos dizer Claudio Ulpiano (2017) "não é uma deficiência do conhecimento, muito mais que isso o problema é aquilo que penetra nos horizontes para torná-los ilimitados e sempre, invariavelmente, a serviço da vida" (manuscrito 14). 
Os processos artísticos, com suas inúmeras metodologias, confrontam os problemas desdobrando-os em uma complexidade ainda maior, mostrando que a sua potência em problematizar é que transforma os obstáculos em meios. O design também confronta problemas, mas historicamente a sua atitude frente ao problema, a sua metodologia projetual, sempre teve por finalidade uma solução imediata e prática dos problemas através da criação de objetos de uso específico. De acordo com Rafael Cardoso (2011), o pensamento clássico do design se esquece da precariedade da forma. Esse desgaste termina por transformar as antigas soluções em novos problemas porque "ao sobreviverem além da finalidade para o qual foram pensados, os objetos acabam resistindo aos seus projetos" (p.125).

Porém, o design contemporâneo ao se contagiar desse desejo de complexidade que marca nossa época, se abre para projetos que se descolam da prisão das funções, da universalidade dos propósitos, da simplificação de resultados para um campo mais livre e complexo, no qual o design é visto como um sistema de relações do homem com o seu entorno. Relações essas que são mutantes. Assumem que as representações de mundo possuem um equilíbrio precário e sabem que os significados são frutos de processos de significação em fluxo contínuo.

Se criarmos projetos pensando além das suas funções práticas e supracodificadas, alcançaremos outras camadas de sentido que extrapolam as clássicas questões de forma e funcionalidade do design tradicional em direção aos deslocamentos sensoriais e temporais da experiência estética. $\mathrm{O}$ condicionamento estrito da forma à função retira do usuário a experiência estética do objeto, a possibilidade de empatia e, por isso mesmo, inibe a sua capacidade de produção de sentido. Para Cardoso (2011) a questão da durabilidade dos objetos está mais nos sentidos e menos nos materiais e na engenharia. Para um artefato resistir ao seu desgaste ele precisa ser capaz de produzir significados, simbolizar outros valores para além dele próprio.

O design que problematiza abraçando a complexidade do mundo contemporâneo não trabalha em prol da redução simplificadora das inúmeras variáveis, ao contrário, amplifica as alternativas e as possibilidades de soluções. Para tal, o designer será convocado a construir uma linguagem sua que o aproximará das práticas expressivas da atividade artística, do pensar/fazer que constrói uma poética própria através da materialização de ideias. $E$ tal como a obra de arte, a obra do designer precisa da participação do fruidor/usuário, por isso a sua significação é um processo aberto em germinação contínua, no sentido dado por Umberto Eco (1991), permitindo a atribuição de novos significados abertos "a um a série virtualmente infinita de leituras possíveis que leva a obra a reviver segundo uma perspectiva, um gosto, uma execução pessoal" (p.64).

No prefácio do livro A forma segue a ideia (Naylor e Ball, 2005), destaca-se a importância de pensar os trabalhos em design sob a perspectiva da poesia, assumindo que Design e Arte podem e devem constituir um território em comum.
Naylor e Ball são categóricos ao afirmarem que a inesgotável repetição dos modelos de pensamento que demoram em libertar-se do funcionalismo modernista, provocando uma falta de criatividade generalizada, se deve justamente à falta de poesia. Para além dos binômios forma-função ou forma-ideia, o que interessa aos autores nos trabalhos de design é a mediação crítica que suas formas promovem, questionando os valores e significados dos discursos dominantes e sugerindo novos rumos, constituindo novas concepções culturais. Os objetos e peças gráficas mais triviais poderão surpreender ultrapassando a sua mera serventia, revelando um novo significado. É nesse sentido que poderemos qualificar como poético um objeto do design, sempre que o seu uso seja transcendente à sua previsível funcionalidade.

Por isso é imperativo conferir à obra de design semelhante densidade poética, semelhante capacidade de gerar novas significações. Se o sentido da obra de arte resiste através do tempo é devido à sua capacidade de atualização dos sentidos nela implicados e multiplicados. Só assim os objetos da nossa sociedade industrial não se transformarão em dejetos. De acordo com Cardoso (2012), se isso assim acontece, não é porque esses objetos deixaram de cumprir suas funções, mas sim porque perderam o seu sentido. Vale aqui trazer um exemplo que o autor cita em seu livro Design para um mundo complexo: o objeto WW. Stool, de Philippe Stark, que não possui uma função precisa, podendo se desdobrar em banqueta, suporte para coisas indefinidas ou mesmo objeto escultural para deleite estético.

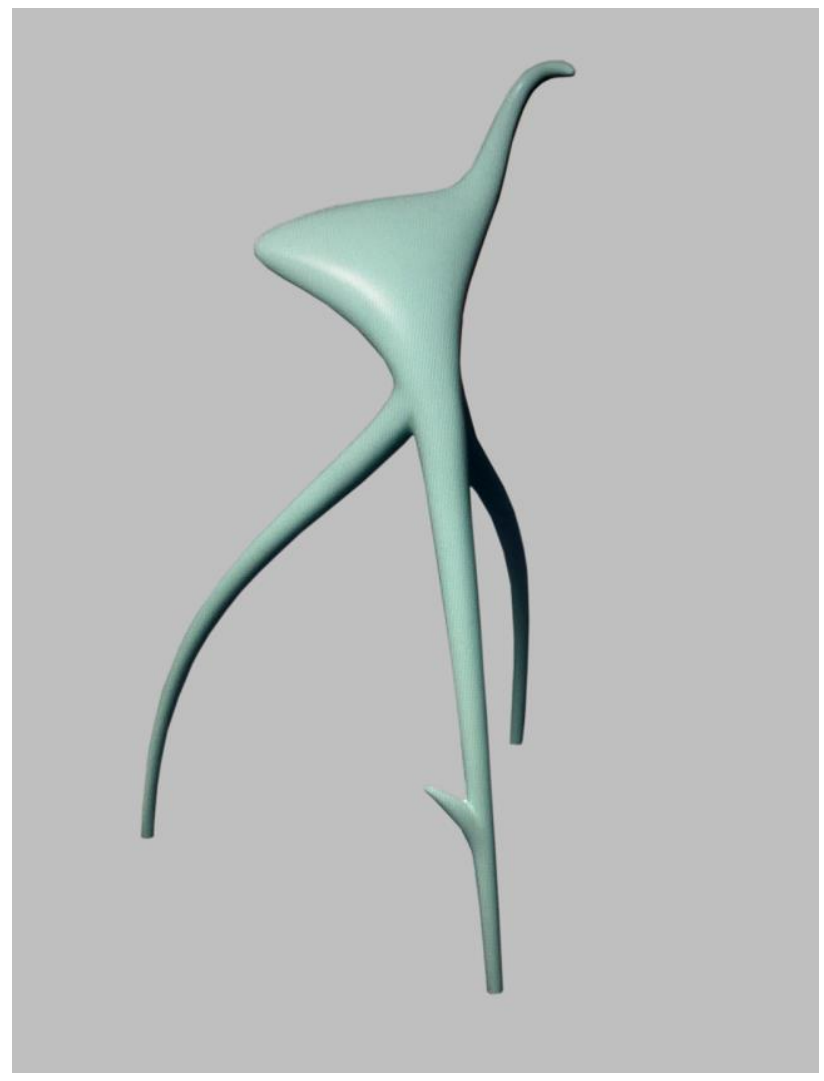

5

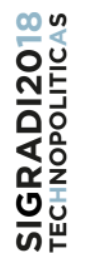

Figura 8: Objeto WW. Stool de Philippe Stark. Fonte: Autores.

Segundo o sociólogo Henry-Pierre Jeudy (1999), o artefato de Stark tem por função "a possibilidade de não 
ser utilizado" (p. 48). Ou seja, o diferencial no projeto de design do objeto WW. Stool é exibir simultaneamente o seu potencial de ser e não ser um objeto funcional.

Essa "potência de não ser" encontra afinidade com o pensamento de Agamben (2018) em seu ensaio O que é 0 ato de criação. $O$ autor recorre ao conceito de potência em Aristóteles, que une, ao mesmo tempo em que confronta, potência (dynamis) ao ato (energeia). Será por meio desse confronto que o filósofo grego vai explicar os atos de criação que para ele eram compreendidos como o exercício das artes em seu sentido mais amplo (technai). Assim, quem possui uma capacidade ou habilidade é porque possui uma potência que pode ser posta em ato ou não. O arquiteto, exemplo dado por Aristóteles, é definido pela possibilidade de desempenhar ou não seu ofício. Por isso, o arquiteto ou o músico, mesmo quando não está exercendo a sua atividade, não deixa de ser arquiteto ou músico. Para Agamben, "a potência, esta é a tese genial de Aristóteles, mesmo que aparentemente óbvia, é definida essencialmente pela possibilidade de seu não exercício" (p. 63).

A tese aristotélica define a ambiguidade intrínseca de qualquer potência humana de ser e de não ser, de fazer e não fazer, constituindo assim o que seria a essência da potência: "a sensação é constitutivamente anestesia; o pensamento, não pensamento; a obra, inoperosidade" ( $p$. 65). Conceber a potência criativa ou a potência de um projeto em relação direta com a própria impotência, ou seja, a potência de poder não passar ao ato é assumir uma liberdade, uma inoperância que possibilita um pensamento crítico sobre si mesmo. Seria "esse resto inoperante de potência que torna possível o pensamento do pensamento, a pintura da pintura, a poesia da poesia" (p. 75) e o design do design.

O valor conferido aqui à inoperosidade é importante para compreender porque é tão fascinante a ideia implicada no objeto WW. Stool de poder ou não exercer a sua função de uso. Essa perspectiva abre para o design uma via complexa e problemática, que desativa e torna inoperantes as funções pré-estabelecidas de utilidade, de comunicação e informação dos objetos e/ou peças gráficas, possibilitando um novo uso, imprevisto, impensável. Esse é o procedimento da poesia com a linguagem, "é o ponto em que a língua tendo desativado suas funções utilitárias, repousa em si mesmo, contempla a sua potência de dizer" (p. 80). Por isso, esse é também o ponto em que o design pode constituir uma poética. E o que a poesia realiza pela potência de dizer, o design deve realizar pela potência de projetar e significar. Considerando a possibilidade de inoperância de usos e funções, o design acolhe a incerteza da vida e passa a "projetar de modo mais aberto, ou seja, de modo a gerar projetos resistentes ao seu engessamento formal e eventual obsolescência" (Cardoso, 2011, p.75).

Aqui podemos aproximar a noção de inoperância em Agamben com a noção do improdutivo em Groys. Ambas as noções encarnam o terror do homem moderno frente a qualquer coisa que the parecesse inútil ou perda de tempo. Por isso que na contemporaneidade coube aos artistas e aos criadores de todas as áreas questionar a cadeia produtiva que rouba do homem 0 direto à hesitação e reflexão. Esse questionamento se faz através de projetos que positivam a vida contemplativa (otium) em vez do modo negativo da vida (o negotium), que impede o homem, aprisionado na lógica do mercado, de pensar a si mesmo abrindo novas possibilidades de existência.

\section{CONCLUSÃO}

Podemos nos servir das confluências entre design e os processos criadores para pensar o design contemporâneo através de estratégias que articulem pensamentos de outras áreas do conhecimento sob a perspectiva da multiplicidade de meios. Essa variedade de meios interatuando, essa capacidade do pensamento criador em incorporar o mundo e se alargar nele, configurou o que Rosalind Krauss (2006) chamou de "campo expandido" um campo sem limites onde o artista, pode trabalhar fora da pureza de uma técnica ou meios tradicionais. Essa noção de campos ampliados também se aplica ao design.

Por isso a ideia de fazer projetos gráficos de livros de artista, usá-los como plataforma para as minhas pesquisas nas fronteiras entre design e arte. Provocantes, afeitos às especulações poéticas, os livros de artista são mananciais de sensibilidade. Criá-los implica em diálogos sinestésicos: a manipulação íntima de superfícies que convidam ao tato, ao olfato, a ver de perto. São volumes no espaço que abrigam no seu interior outros espaços, também percebidos como sequência de momentos cuja ordem de leitura pode se tornar arbitrária. O perambular pelas páginas, essa leitura fragmentada, suspende a macro visão da coerência e preserva o fabuloso na autonomia do detalhe.

O projeto Poor Fish Memories foi realizado de forma a ativar, provocar estados difusos que acendem/ascendem entre o que chamamos, de forma simplificada, de realidade e imaginário. Não há pressa em sua leitura, não exige que algo esteja pronto de imediato, não simplifica. Pode ser visitado, revisitado, manuseado negligentemente ou com extremo rigor. Esse livro-objetopoético quer suspender, expandir o tempo, oscilando entre a variada gama que vai do tempo escasso ao tempo excessivo, transformando essa exiguidade em demasia ou coabitando essas temporalidades.

Por isso também, a ideia de projetar uma versão digital de algo tão afeito às percepções táteis foi tão desafiadora. Para tal, foi preciso deixar que a intuição criadora fosse a guia e não recusar a possibilidade de novos vínculos, novas conjunções entre coisas e pensamentos, formas e valores, design e arte.

Atuar nos campos ampliados do design é oxigenar clássicas questões projetuais, tais como concepção, pesquisa, criação de formas e interação com o usuário, através dos deslocamentos provocadores que criação artística promove. Como disse Agamben (2007), é vislumbrar a "via de felicidade que se abre" (p. 60) quando deslocamos uma disciplina de sua finalidade, quando poetizamos um saber.

\section{REFERÊNCIAS}

Agamben, G. (2008). Qu'est-ce que le contemporain? Paris: Payot \& Rivages.

Agamben, G. (2018). O fogo e o relato. São Paulo: Boitempo. 
Antoun, H. (1990). Folheto da exposição Do infinito do olhar ao finito do visto. Rio de Janeiro: Espaço Cultural Sergio Porto.

Ball, R,; Naylor, M. (2005). Form follows idea. London: Black Dog Publishing.

Cardoso, R. (2012). Design para um mundo complexo. São Paulo: Ed. Cosac Naify.

Deleuze, G., Guatarri, F. (1992). O que é Filosofia? São Paulo: Ed. 34.

Eco, U. (1991). A obra aberta. São Paulo: Ed. Perspectiva.

Groys, B. (2009). Comrades of Time. e-fluxjournal\#11, 01-11. Retrieved from https://www.librarystack.org/e-flux-journal-11/
Jeudy, P.(1999). Philippe Starck: ficção semântica, in Arcos: Design, Cultura e Materialidade, v. 2. Rio de Janeiro: PPGD/ESDI \& Contracapa.

Klee, P. (2007). Teoría del arte moderno. Buenos Aires: Cactus.

Krauss, R. E. (2006). La originalidad de la Vanguardia y otros mitos modernos. Madrid: Alianza Editorial.

Tunga (2017.). Pálpebras. São Paulo: Galeria Millan.

Ulpiano C. (2017). Transformar obstáculos em meios. Retrieved from https: acervoclaudioulpiano.com/2017/ manuscrito14/

Valéry, P. (1998). Introdução ao método de Leonardo da Vinci. São Paulo: Ed. 34. 